\title{
O Papel da Mulher na Sociedade.
}

\author{
Teresa Ancona Lopez de Magalhães \\ Professora Assistente Doutora nas Faculdades de Direito \\ da Universidade de São Paulo e na Pontifícia Universidade \\ Católica de São Paulo.
}

\section{Considerações Gerais.}

Dada a importância do tema, tenho que dizer que, apesar de ser esposa, mãe de família e profissional, sinto uma dificuldade imensa em chegar a conclusões cabais sobre o papel da mulher, pois, hoje em dia, não existe assunto mais polêmico mais empolgante, mais controvertido e mais mal interpretado como a própria mulher. atual?

Qual, então, o verdadeiro papel da mulher na sociedade

Evidentemente, esses papéis são vários: ora é ela dona de casa, esposa, mãe de família, ora enfrenta a chamada dupla jornada de trabalho, é a profissional, trabalhando no lar e fora dele, ora é a mulher que luta para ter uma participação efetiva na sociedade da qual é membro. Enfim, a mulher tem que desempenhar vários papéis e o importante é que ela não se veja, em todo esse cenário, somente como mulher mas, antes de tudo, como ser humano e, dessa forma, procure fazer sempre alguma coisa que a complete, que a realize.

Todavia, penso que o fulcro de todo o debate que se trava em torno da mulher é a luta que diariamente ela enfrenta para alcançar sua justa posição de igualdade em relação ao homem. Como é óbvio, trata-se de igualdade social, política e econômica, respeitando-se as características e as tendências naturais de cada sexo, reivindicando-se, apenas, oportunidades sociais iguais para todos, sem discriminações de espécie alguma, e é neste ponto que a luta feminina ganha sua grandeza. 


\section{O Princípio da Igualdade.}

O imenso rol de reivindicações femininas pode se resumir apenas em uma única - que seja obedecida a regra genérica que define a igualdade de todos perante a lei, ou melhor, que não seja mais ferido o chamado princípio da igualdade que está assegurado no artigo $153, \S 10^{\circ}$ da Constituição Federal, Emenda n. ${ }^{\circ} 1$, de 1969 , pelo qual todos são iguais perante a lei, sem distinção de sexo, raça, trabalho, credo religioso e convicções políticas.

$\mathrm{Na}$ verdade, essa regra de Direito se baseia em um princípio de Direito Natural, e portanto de Justiça, de que todos nascemos iguais e porisso devemos ser tratados igualmente.

A igualdade, desde a Antigüidade, está indissoluvelmente associada à democracia, é expressão direta de um regime democrático (Cf. MANoel Gonçalves Ferreira Filho, Curso de Direito Constitucional, 4. ${ }^{\mathrm{a}}$ Ed., Saraiva, 1973, p. 267, SP). No Brasil o princípio constitucional de igualdade existe desde a Carta de 1824 e está em todas as Constituições Republicanas - na de 1891, na de 1934, na Carta de 1937, embora contendo regra mais lacônica, na Constituição de 1967 e na Emenda n. ${ }^{\circ}$ 1, de 1969.

Todavia, apesar de ser norma constitucional, baseada na idéia de justiça e hierarquicamente superior a todas as demais, tem sido, com relação à mulher, freqüentemente descumprida, não só por leis ordinárias e atos administrativos, mas principalmente na vida cotidiana, desde o próprio lar até o trabalho e a participação na vida pública.

Esta discriminação é tão antiga quanto a própria humanidade e é acompanhada pelo desenvolvimento do próprio Direito. Entretanto, pode-se observar que, em alguns momentos, há um incentivo à participação efetiva da mulher tanto nos empreendimentos privados quanto na vida pública. Isto acontece quando, por causa de transformações políticas, a mulher é requisitada para ajudar a construção ou a reconstrução mais rápida de uma nação, sendo, como sabemos, a reserva da mão-de-obra de um país. Como exemplo temos a imensa atuação das mulheres nas sociedades pioneiras, como nos Estados Unidos, Israel, Argélia e, em geral, em todos os países de regime socialista. 


\section{Esboço Histórico.}

Desde a mais remota antigüidade ocupou a mulher na sociedade uma posição subalterna ou, no mínimo, subsidiária ou complementar ao homem.

Assim, em algumas civilizações a mulher foi considerada coisa, podendo ser, por isso, passível de ser comerciada. $\mathrm{Na}$ antiga Assíria as esposas eram tratadas como bens dos maridos. O direito de divórcio era exclusivamente do homem, permitia-se a poligamia e a todas as mulheres casadas era proibido aparecer em público sem um véu na face. Esse foi o início da segregação oriental da mulher (História da Civilização Ocidental, EDWARD MC NALL BURNs, 21.a ed., Ed. Globo, Porto Alegre, 1977, p. 89).

O Código de Manu, na antiga Índia, foi talvez um dos mais rigorosos em relação à mulher. Diz o art. 415 dessa lei que "a mulher durante a sua infância depende do pai; durante a mocidade do marido; em morrendo o marido, dos seus filhos; se não tem filhos, dos parentes próximos de seu marido; porque uma mulher nunca deve governar-se à sua vontade" (Fustel DE Coulanges, $A$ cidade Antiga, $1 .^{\circ}$ v., tradução de Sousa Costa, 2. ${ }^{\mathrm{a}}$ ed., Livraria Clássica, 1919, Lisboa, p. 144 - JaYme De Altavila, Origem dos direitos dos Povos" 2. ${ }^{\mathrm{a}}$ ed., Melhoramentos, SP, pág. 54).

As leis romanas e gregas mais antigas repetiam mais ou menos esses preceitos, pois a mulher estava sob o poder marital que para os romanos era chamado "manus" Da "manus" do pai ela passava para a "manus" do marido, morto este para a tutela dos filhos e na falta destes para a tutela dos parentes do marido. 0 marido podia também, antes de morrer, designar tutor para ela (FUSTEL DE COULANGES, op. cit., p. 144).

$\mathrm{Na}$ época áurea da civilização grega (séc. V e IV a.C). especialmente em Atenas, embora o casamento continuasse a ser uma instituição importante para a procriação dos filhos que se tornariam cidadãos do Estado, há razão para se crer que a instituição da família tivesse declinado. Os homens de classe mais próspera passavam a maior parte do tempo longe da família. As esposas, relegadas a uma posição inferior, deviam permanecer reclusas em casa. O próprio casamento assumiu o caráter de arranjo político e econômico, destituído de elementos românticos. Os homens casavam para assegurar a legitimidade de alguns filhos e para adquirir propriedade pelo dote e também ter alguém para tomar 
conta da casa. Mas os maridos não consideravam as esposas como suas iguais e não apareciam em público com elas, nem encorajavam sua participação em qualquer forma de atividade social ou intelectual (BURNS, op. cit., p. 190).

o direito grego, o romano e o hindu sempre consideravam a mulher como menor. Ela nunca poderia ter um lar para si, não era nunca o chefe do culto doméstico. Em Roma recebia o título de "mater-familias", mas perdia-o se seu marido morresse.

Mesmo nestas sociedades patriarcais algumas vezes a mulher podia chegar a diversos postos como, por exemplo, comerciante na antiga Babilônia e juiz na organização política hebráica, como no caso de Débora (JAYme DE ALTAvila, op. cit., p. 54).

Mas foi, talvez, no Egito antigo que mais prestígio alcançou a mulher. A família egípcia era monogâmica, nem o faraó podia ter mais que uma esposa legal. As esposas egípcias gozavam de uma situação invejável, pois na realidade a família egípcia era quase matriarcal. A descendência traçava-se pela linha feminina e a autoridade do avô materno era maior do que do próprio pai. Foram os egípcios quase os únicos dentre os orientais que permitiam às mulheres a sucessão no trono (BURNS, op. cit., p. 70).

$\mathrm{Na}$ verdade, a origem do poder do homem sobre a mulher e os filhos foi na religião. A autoridade dentro da família antiga era o deus doméstico. E era o marido que desempenhava as elevadas funções religiosas. Quando morria passava a ser o antepassado que os descendentes invocariam. A religião não colocava a mulher num lugar tão elevado. Ela não era a senhora do lar. A sua religião não lhe vinha por nascimento, mas era iniciada pelo casamento. Ela não representava os antepassados, pois que não descendia deles. Também não se tornaria antepassado. Tanto na vida como na morte era considerada um membro de seu esposo. As crenças religiosas colocavam o homem acima da mulher. O que prova isto é que a mulher que não casava segundo os ritos sagrados e que, por conseqüência, não tinha sido associada ao culto, não estava subordinada ao poder marital (F. DE CoUlANGES, op. cit., p. 145).

Na Idade Média a subordinação e a inferioridade da mulher até pioraram com relação a algumas civilizações antigas. Houve um Concílio no qual os teólogos deveriam refletir muito antes de admitir que a mulher tinha alma, isto 
é, se se situava acima do nível dos animais (ROBERT GUBBELS, Le Travail au Féminin, Ed. Gerard, Bélgica, 1967, p. 13).

O Estado moderno nasce no Séc. XVIII preocupado em assegurar, acima de tudo, a liberdade. A Revolução Francesa em 1789 colocou ao lado da liberdade a igualdade. Todas as Declarações do Séc. 18 e as subseqüentes adotaram o princípio da igualdade perante a lei e, nesta época, começam a surgir os movimentos propondo a igualdade também da mulher em relação ao homem, conforme pudemos constatar através do Boletim da Unesco no Ano Internacional da Mulher sobre o progresso dos direitos da mulher.

\section{o Papel da Mulher na Família e o Direito de Família.}

O Direito, existindo em função da sociedade, deve sempre acompanhar o desenvolvimento do fato social. Assim, de nada adiantam normas que não acompanham a realidade, pois serão fatalmente condenadas à ineficácia social, apesar da eficácia jurídica poder, a qualquer tempo, ser argüida.

o Direito da Família brasileiro sempre evoluiu acompanhando o progresso da sociedade no sentido da melhoria da condição da mulher. Mas, essa evolução foi e está sendo em ritmo mais lento que o desenvolvimento cultural. Apesar disso, se compararmos o atual Código Civil, que é de 1916, com a lei anterior, isto é, as Ordenações do Reino, que vigoraram até aquela data, veremos que realmente houve uma radical mudança. Estabeleciam as Ordenações, por exemplo, que não constituia ato ilícito castigar criado ou discípulo ou sua mulher ou seu escravo.

Com o advento do Código Civil acabou o poder marital passando a mulher a ser consorte e companheira do marido, sendo este o chefe da sociedade conjugal. No entanto, o art. $6 .^{\circ}$ colocava a mulher entre as pessoas relativamente capazes, isto é incapazes juridicamente para a prática de certos atos, ao lado dos silvícolas, dos menores entre 16 e 21 anos e dos pródigos. Também pode ser lembrado o art. 393 que tirava da viúva que contraía novas núpcias o pátrio poder em relação aos filhos do primeiro leito.

O grande passo que deu nossa legislação civil, no sentido da igualdade da mulher em relação ao homem, foi a Lei 4.121 de 27 de agosto de 1962 - O Estatuto da Mulher Casada que derrubou uma série de dispositivos preconceituosos e discriminatórios, como, além dos citados anteriormente, todos 
os que eram decorrência direta de considerar-se a mulher menos capaz que o marido. Hoje é esta lei combinada com a Lei do Divórcio (Lei 6.515 de 1977), que rege a posição da mulher dentro da família. O Projeto de Código Civil de 1975, apesar de ter extirpado alguns absurdos, como o dispositivo que trata da anulação do casamento por defloramento da mulher ignorado pelo marido, contém ainda resquícios que não condizem com o nosso atual estágio cultural. Repete textos anacrônicos do Código Civil com algumas modificações. Entre tais conservadorismos podemos apontar o da direção da sociedade conjugal que continua sendo do marido, o da prevalência da vontade do pai no caso de casamento de filho menor, a mesma coisa quanto ao pátrio poder e administração dos bens do casal, além de tantos outros.

Em conclusão, continua a nossa lei civil insistindo em que a família seja dirigida pelo homem e que seja a opinião deste que deva prevalecer no caso de discordância entre o casal, restando, algumas vezes, o direito da mulher recorrer ao juiz. A mulher tem, entretanto, a obrigação legal de colaborar no sustento da família quando os rendimentos do marido forem insuficientes.

Todavia, apesar das normas de Direito de Família serem ainda cliscriminatórias, ferindo, dessa forma, o princípio constitucional da igualdade, na prática o quadro familiar é outro. Apesar do homem ser juridicamente o chefe da família, o cabeça do casal, sabemos que de fato o papel marcante dentro da família é o da mãe, não só porque tem mais contato com os filhos mas também porque é ela que mantém o equilíbrio deste pequeno núcleo. Aqui não se trata de supervalorizar o papel da mulher, trata-se apenas de mostrar a realidade como ela é. Basta atentarmos para os casos de pessoas desajustadas socialmente e veremos que, na maior parte das vezes, procedem de famílias onde a mãe não se portou com a dignidade devida. O mesmo não acontece, em geral, quando é o pai que toma atitudes menos honrosas.

A mulher é, na verdade, a base da família, a base da sociedade. Por tudo isso é que se torna imperiosa a adaptação da lei à realidade social, com a instituição, de uma vez por todas, do regime democrático também dentro da família, onde ambos, pai e mãe, tenham os mesmos direitos e as mesmas obrigações, observadas, evidentemente, as diferenças existentes entre os papéis que a cada um cabe dentro da sociedade doméstica. 


\section{O Papel da Mulher diante do Trabalho.}

Está aqui a origem próxima de todo debate sobre a emancipação da mulher, sendo, inclusive, o tema preferido de todos que cuidam do assunto.

A primeira consideração que deve vir à baila sobre o trabalho da mulher é o duplo aspecto que pode assumir, isto é, dentro e fora do lar.

Na CPI da Mulher, realizada durante o ano de 1977 no Congresso Nacional, este foi um dos temas mais debatidos. Uma das depoentes (Carmen Lúcia de Melo Barroso) deixou claro que não se pode afirmar que a mulher brasileira tenha estado ausente na tarefa de construção da riqueza do país. É verdade que sua atuação tem sido pouco visível se examinarmos livros de história ou jornais verificamos que sua contribuição é praticamente ignorada e, no entanto, tem sido de sua exclusiva responsabilidade a execução de tarefas imprescindíveis à manutenção do trabalhador e sua prole. Que aconteceria se a mulher se recusasse a cumprir a sua jornada como dona de casa e mãe de família?

Economistas vêm se preocupando com o valor monetário do trabalho doméstico e as estimativas são animadoras acreditando que esse trabalho é de fundamental importância para a economia nacional. Em determinadas camadas da população a dona de casa recebe, indiretamente, através do salário do marido contribuição muito inferior ao que receberia se essa atividade fosse remunerada.

Relativamente à participação da mulher no mercado de trabalho, no Brasil ainda é muito pequena, apesar de que essa participação tem subido sensivelmente desde 1973. A causa do aumento parece ser a aplicação do mercado de trabalho pela criação de novos empregos e a diminuição, na última década, dos níveis de renda real de grande parcela da população brasileira, tornando dessa forma necessária a participação da mulher para complementação do orçamento doméstico. Mesmo assim a taxa de atividade feminina no Brasil é ainda muito pequena em relação aos outros países do mundo (em 1960 ocupava o último lugar) e apesar do aumento, é a quinta parte da atividade remunerada no Brasil. O problema se agrava quando consideramos as regiões menos desenvolvidas do Brasil. $\mathrm{E}$ em todas as regiões as mulheres mais segregadas são as casadas que sofrem, apesar de proibição legal, uma série de restrições (Cf. CPI da Mulher, depoente citada). 
No entanto, dados mais assustadores são aqueles que as estatísticas não mostram, são os que se referem à segregação ocupacional e salarial. Este é um dos pontos mais chocantes da discriminação entre homens e mulheres, pois a mulher quando sai para exercer uma atividade remunerada encontra menos oportunidades no mercado de trabalho, trabalhos menos gratificantes e realizadores, salários mais baixos para exercer exatamente a mesma atividade masculina, menos prestígio e condições de trabalho piores que as dos homens. Além de tudo isso, toda mulher que trabalha fora de casa continua arcando sozinha com toda a responsabilidade das tarefas domésticas é a chamada dupla jornada de trabalho, sem descanso e sem férias (Cf. CPI da Mulher, depoente citada).

Numa pesquisa feita em 1971 pela USP, verificou-se que os homens tinham salário 57\% maior que o das mulheres nas indústrias paulistas. Mesmo nas funções consideradas femininas como a de secretária, o salário do homem é cerca de $25 \%$ maior.

Por que se encontra a mulher nessa posição perante 0 trabalho?

Acho que a primeira e fundamental razão, da qual derivam todas as outras, é o tratamento tradicionalmente desigual entre a mulher e o homem. Criou-se a imagem da mulher como um ser fraco, dependente, submisso, cuja principal função é criar filhos. Lutar contra essa tradição de milênios não é fácil. Talvez eu pudesse ir mais longe e perguntar: por que essa tradição? Penso que a origem remota da sociedade patriarcal só pode ser a força física que o homem sempre teve maior que a mulher. Foi daí, dessa superioridade muscular, que a desigualdade começou. Mas este é outro problema.

A segunda porque sempre foram os homens que fizeram as leis e dirigiram os destinos das nações, com raríssimas exceções.

A terceira porque a própria mulher assumiu passivamente este papel que lhe impuseram e só sai de casa para trabalhar, seja ela solteira ou casada, quando precisa desse ganho para seu próprio sustento ou para complementação do orçamento doméstico. A conclusão lógica é que o seu trabalho é tratado como subsidiário e, portanto, o tipo de emprego e salário vão ser encarados subsidiariamente.

o quarto aspecto é relacionado diretamente ao anterior. A mulher não se vê como um membro da sociedade igual aos outros, se vê apenas como mulher, dona de casa, mãe de 
família. Há um autodesprestígio. Assim, vai trabalhar não porque o trabalho vai realizá-la como ser humano, mas pelos motivos acima aludidos. Ora, a mulher brasileira não tem espírito profissional, ou, dizendo a mesma coisa em outras palavras, a mulher brasileira tem espírito amadorístico quanto ao seu próprio trabalho. Em conseqüência ela se desprestigia e também desprestigia as suas iguais, não confiando nelas profissionalmente. Como exigir isto dos homens?

A quinta razão é a falta de competência intelectual e profissional. Neste aspecto a culpa, quase que totalmente, é da sociedade que não lhes deu condições. As mulheres que chegaram a altos cargos foi única e exclusivamente devido à sua cultura e aptidão. Aliás, com os homens acontece quase a mesma coisa.

Finalmente, o último e mais grave motivo do baixo contingente ativo feminino diz respeito especialmente à mulher de condição econômica inferior. É a falta de creches e pré-escolas. Este é realmente o problema mais sério com relação ao trabalho da mulher e, neste ponto, a responsabilidade não é só do governo, como querem alguns. Não devemos esperar tudo do governo, é impossível. A responsabilidade é de todos nós, de toda a sociedade. Também neste caso a maternidade é um problema social e não individual ("La maternité est une fonction sociale qui doite être assumée par l'ensemble de la societé et il est lâche de laisser à la mère le soin de resoudre tant bien que mal, c'este-à-dire à son propre détriment, les problèmes qu'elle pose", ROBERT GUBBELs, op. cit., p. 39).

A legislação trabalhista brasileira é uma das mais adiantadas do mundo e até um pouco protecionista com relação à mulher, o que caracteriza o espírito patriarcal e vem, por isso, às vezes, prejudicar a própria mulher.

$\mathrm{Na}$ verdade, é na prática que o problema se torna grave. As oportunidades são realmente diferentes. Nunca, por exemplo, tivemos uma mulher ministro, governador, desembargador ou até mesmo juiz de varas cíveis e criminais, pelo menos em São Paulo. (Recentemente, depois que este artigo já estava no prelo, foi nomeada a primeira juíza cível de nossa Capital.) Até o feminino de alguns destes cargos ou funções inexiste ou causa estranheza. "Governadora" por exemplo, é definida pelos dicionários como a mulher do governador. Por quê?

Em resumo, o Brasil está na vanguarda do cenário jurídico internacional sendo sua legislação quase perfeita em termos de coibir a discriminação. Basta lembrar, por exemplo, que foi o Brasil o primeiro país latino e também da América 
do Sul a conceder o direito de voto à mulher, em 1932 pelo Código Eleitoral, direito esse reafirmado através da Constituição de 1934. Também em 1932 foi regulado aqui o trabalho feminino dando proteção à operária na indústria e comércio.

Mas, como vimos, a realidade é outra e há uma efetiva discriminação no tipo de trabalho e no salário. A maioria das mulheres, qualitativamente, se encontra nas atividades de empregada doméstica, trabalhadora rural e professora primária, sendo que as duas primeiras não são protegidas pela CLT.

\section{Conclusões.}

Depois de todo esse balanço, o que fazer para chegar à igualdade assegurada perante a lei? Qual a melhor maneira da mulher derrubar essa tradição de séculos? Talvez, o movimento feminista?

Os movimentos visando essa igualdade começaram no século XVIII como conseqüência das declarações liberais. Poderíamos lembrar, por exemplo, que na França em 1788. CONDORCET, político conhecido, defende o direito da mulher à educação, ao trabalho e à política. Na Inglaterra em 1792, aparece MARY WOLLSTONECRAFT, pioneira da ação feminista, com o livro $E m$ defesa da mulher.

Mas o movimento feminista propriamente dito, como é conhecido atualmente, lançou suas raízes com o livro de Simone Beauvoir, O Segundo Sexo, no início da década dos 60, só eclodindo, no entanto, no cenário mundial nos anos 70 e no Brasil a partir de 1975.

Pessoalmente discordo totalmente do movimento feminista, nos moldes que nos está sendo apresentado, porque não passa de uma luta radical onde o que se quer é acabar com o poder masculino substituindo-o pelo poder feminino. $\mathrm{Na}$ verdade, este movimento não valoriza a mulher como ser humano, membro da sociedade, mas apenas pelo fato de ser mulher e por isso mesmo "superior ao homem", ferindo, desse modo, o princípio da igualdade e sendo, portanto, antidemocrático.

Tristemente, está conseguindo distorcer a imagem da mulher, criando, desta forma, seu arremedo e, assim, desgastando a própria mulher e atrasando sua almejada emancipação.

Poderia lembrar como exemplo, os debates que se travam sobre a libertação sexual da mulher. Esta "libertação" é decantada como o direito que tem a mulher de fazer o que 
quiser de seu próprio corpo. Na prática tal assertiva tem funcionado como o direito de fazer propaganda pelos "feitos" conseguidos tanto em quantidade, como em qualidade. Ora, com essa suposta libertação, está a mulher se desvalorizando cada hora mais, pois tais atitudes não passam de demonstração de insegurança e de autodesprestígio por mais paradoxal que isso possa parecer.

Além do mais, não são discussões apaixonadas que vão resolver o problema como, por exemplo, a acusação de que a posição subalterna da mulher é fruto do sistema capitalista, porquanto a mulher seria mais um dos bens de consumo (mulher-objeto). Isto só demonstra falta de idoneidade intelectual das argumentadoras do "discurso feminino", pois a mulher se encontra nessa posição desde que o mundo existe e não há, em contrapartida, nos países comunistas nenhuma mulher Chefe de Estado, Ministro ou Secretário Geral de Partido.

Finalmente, o movimento feminista vem de cima para baixo, das elites intelectuais das universidades para o povo. Imagina-se abstratamente que tais e tais reivindicações sejam de todas as mulheres, igualando totalitariamente todos os seus anseios. Ora, a solução do problema não é tão simples assim. $\mathrm{Na}$ verdade, a causa da mulher depende muito mais da classe social a que ela pertence do que do fato dela ser mulher. Se fizerem uma mesma pergunta a uma doméstica, a uma profissional liberal e a uma mulher da chamada alta sociedade, as respostas serão totalmente diferentes, dependendo das expectativas de cada uma dentro do seu meio social. Pesquisa feita em São Paulo, entre operárias, mostrou que a sua principal meta é o casamento, desmentindo, assim, mais uma proposta feminista.

Todavia, o movimento feminista tem um mérito que, por justiça, não the deve ser negado. Foi ele que alertou, apesar de agora ter se desvirtuado de seu digno fim, a mulher para toda a sua problemática.

Qual o caminho?

Penso que nem a acomodação, nem o radicalismo oposto que só leva ao espírito competitivo e desgasta o verdadeiro valor da mulher. Só no dia em que a mulher assumir seriamente e conscientemente cada um dos papéis que lhe foram destinados é que conseguirá a igualdade sócio-política tão almejada. 
Assim, além de desempenhar seu papel máximo que é a maternidade, pois é ela que vai forjar a geração seguinte, além de ser a companheira do marido, apoiando-o e criando circunstâncias para que ele se realize, deve desempenhar com a maior seriedade possível seu papel de profissional e mais ainda, e aqui vem o ponto mais importante para a sua emancipação, deve participar ativamente da vida de sua comunidade, de seu país. Diria que a mulher deve intervir em todos os aspectos da vida social e da vida política, não ficando sempre passivamente esperando que as benesses venham do alto. Deve, enfim, impor-se, conquistar sua própria posição pelo que ela é como ser humano que tem direito a uma realização. De outro lado, como é óbvio, não achar que os direitos reconhecidos vieram como um favor dos governantes ou dos homens que influem na vida da nação, mas que, apenas tais pessoas estão cumprindo uma obrigação que lhes está adstrita, que é a de sanar as injustiças sociais.

Enfim, só a mulher que desempenhar efetivamente cada um de seus papéis poderá contribuir para o desenvolvimento total de uma sociedade e é exatamente e somente com esse desenvolvimento que essa descabida discriminação vai acabar. 